\title{
Микросканер на базе синхронного двигателя с внешним ротором для тепловизоров третьего поколения
}

\author{
Р.А. Гладков, И.И. Кремис \\ Филиал ИФП СО РАН "КТИПМ", Новосибирск, 630090, просп. Лаврентьева, 2/1 \\ тел: (383) 330-91-06, эл. почта: igor21738@ngs.ru
}

DOI 10.34077/RCSP2019-92

На сегодняшний день возросла необходимость в получени тевловизионного изображения высокого разрешения. В условиях, когда собственное разрешение матрицы не удовлетворяет требованиям производителей тепловизоров. Решением здесь может быть использование микросканера (MC), позволяющего осуществлять сдвиг проекции изображения в плоскости матрицы на величину до нескольких пикселей. При этом МС способен решить ряд задач, таких как увеличение разрешающей способности тепловизора и устранение дефектов изображения [1].

Существует несколько вариантов микросканеров, разработанных в Филиале ИФП СО РАН «КТИПМ», различных как по принципу работы привода, так и по значению смещения проекции изображения в плоскости матрицы. МС на основе пьезоэлектрического привода, позволяет получить итоговое изображение с частотой смены кадров 50Гц (т.е. частота переключения полей 200 Гц), но имеет не большое смещение проекции \pm 20 мкм. МС с магнитным приводом позволяет получить смещение больше (до 120 мкм), но частота переключения полей при этом не превышает 100Гц.

Привод на пьезаэлементах (ПЭ), как правило, выполняют с импортными комплектующими, поскольку отечественная база имеет куда более скромные характеристики и стоимость таких элементов высока. Второй привод может не удовлетворять требованиям конечного потребителя из-за низкой частоты обновления кадров (25Гц), что ограничивает сферу его применения.

На настоящее время в Филиале ИФП СО РАН получен новый результат - микросканер позволяющий объединить в себе преимущества указанных моделей и исключить их недостатки.

Основные характеристики:

Потребляемая мощность, Вт

Частота смены полей, Гц

Номинальное напряжение питания, В

Габаритные размеры (диаметр/высота), мм

Интервал смещения проекции, мкм

Macca, кг

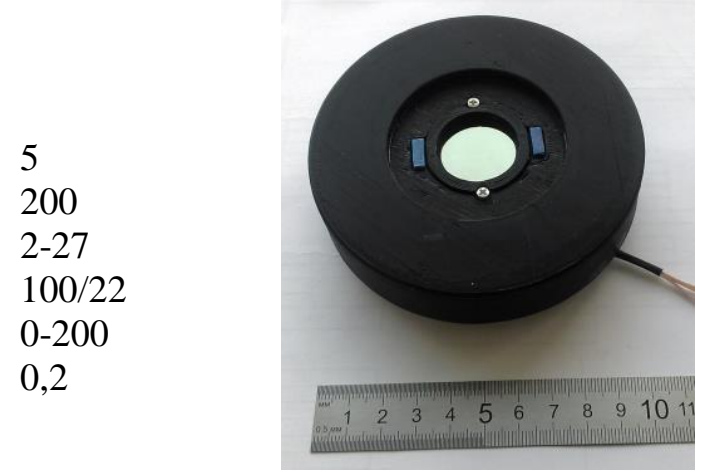

Рис.1.

К дополнительным преимуществам микросканера необходимо отнести технологичность в производстве и низкую стоимость, а также и то, что он выполнен исключительно на отечественной элементной базе. Общий вид микросканера показан на рис.1.

Микросканер использует вращающуюся плоскопараллельную пластинку для смещения проекции изображения. Величина смещения изменяется наклоном пластинки и может гибко настраиваться в диапазоне от 1 до 5 пикселей. Минимальное, для размещения МС, расстояние между компонентами оптики - от 5мм.

Вращение пластинки обеспечивает синхронный двигатель с внешним ротором и датчиком положения. Синхронность управления позволяет привязать угол поворота ротора с моментом регистрации внешней сцены. Сквозная полость позволяет расположить оптический компонент и органы настройки.

\section{Литература}

[1] Кремис И.И, Толмачев Д.А. Гладков// Фильтрация остаточной неоднородности и дефектов изображения в тепловизорах третьего поколения с использованием микро сканирования. Прикладная физика № 1. 2017. 